\title{
The Effectiveness of Group Sandplay Therapy on Quality of Peer Relationships and Behavioral Problems of Korean-Chinese Children in China*
}

\author{
Yeo Reum Lee $\quad$ Mikyung Jang ${ }^{* * * *} \quad$ Jonghee Shim $^{* * * *}$
}

\begin{abstract}
$<$ Abstract $>$
This study is to investigate the effectiveness of group sandplay therapy on quality of peer relationship and behavioral problems of Korean-Chinese children in China and to interpret meaning of sandpictures made by them. Utilizing a mixed-method design, twelve participants (mean age $=11.50$ years, $50 \%$ females) were assigned to three experiment groups with four participants in each group and another 12 children (mean age $=13.50$ years, $50 \%$ females) were assigned to the control group. A total of 8 sessions of group sandplay therapy were provided $2 \sim 3$ times per week for 80 minutes per session. The quantitative results indicated that the group sandplay therapy improved quality of peer relationship and decreased behavioral problems. The qualitative results revealed several common themes such as emptiness, disconnection/ separation, concealment, hindrance/obstruction, connection, upbringing, integration/adaptation. Limitations as well as implications for future research are discussed.
\end{abstract}

Keywords : Group Sandplay Therapy, Korean-Chinese adolescents, Quality of Peer Relationship, Behavioral Problems

* This thesis was written for a 2016 master's program at the Namseoul University.

** Main author, Play therapist at Goyang Areum Children and Adolescent Counseling Center (leesummer723@hanmail.net)

*** Corresponding author, Department of Child Welfare Professor at Namseoul University (jangmiky@hotmail.com) **** Co-author, University of New Hampshire (Jonghee.Shim@unh.edu) 
Journal of Symbols \& Sandplay Therapy, Vol.9 No.2.

\section{I . Introduction}

The Korean-Chinese community in China first started to form in the late 19th century when a number of Koreans migrated to China in search for a new home as their lives on the Korean Peninsula started to fall apart from natural disasters and political confusion. The cultural, economic and social invasion of foreign powers in the early 20th century shattered the spirit of Koreans and infringed on their culture, forcing more people to leave and join the growing Korean-Chinese community in China.

According to Moon-hui Suh (2011), there are two main reasons why the Korean-Chinese population in China demands special attention. First, they are going through significant social change. Second, they make up an important part of the multicultural community in Korea. Although Korean-Chinese are Chinese nationals in the legal sense, many are fluent in the Korean language, which makes it easy for them to come to Korea and find jobs. Some of them eventually settle in and become part of the Korean society.

The ongoing changes in the Chinese society that involve growing skepticism on traditional values, confusion arising from a rapid influx of foreign cultures, inter-generational conflict, and intensifying competition to get into college present tough challenges to Korean-Chinese families, including children (Huh, 2002). Following the cultural norm in China, many Korean-Chinese families choose to have only one child. When parents leave the country to find work elsewhere, the child has no immediate family but only grandparents or relatives to live with.

Ok-hee Park (2000) summed up the main issues of Korean-Chinese adolescents living in Yanbian into three parts. The first issue is overprotection. Overprotected children tend to grow with weakness, frustration and difficulties in interpersonal relationships. As mentioned earlier, most Korean-Chinese families have just one child, so parents are prone to overprotect the child. The second issue is the psychological impact on children whose parents leave home to find work in other countries. Many of these children show poor performance at school, sometimes giving up on their studies entirely, and tend to be rebellious or impulsive. They also suffer from high levels of depression and sense of alienation. Lastly, there is an extremely high 
level of competition among Korean-Chinese families to send their children to the best schools. Children find themselves in an immensely stressful environment, bombarded with heavy study loads and the pressure to excel academically. Furthermore, an increasing number of Korean-Chinese adolescents in China are unhappy with their lives. The rapid changes occurring in the society compounded by psychological pressure, anxiety and discontent that come from the particular ways of life of the Korean-Chinese make life stressful for these children (Lee, 2012). A prior study that compared behavioral problems of Korean-Chinese elementary students in Yanji with their Chinese counterparts revealed a significant difference between the two groups (Kim, 2012).

Stress and overprotection in childhood influence peer relationships, personality and psychological development of children all the way up to adulthood, with adverse effects on their mental health and personality development. In particular, school-age children are relatively more sensitive to peer relationships, as they spend a significant amount of time with peers and start to develop close friendships (Kim \& Jung, 2011). Children who are unable to interact properly with their peers are more inclined to have behavioral problems and suffer from loneliness, emotional frustration, depression and sense of isolation (Yang, 2013). Moreover, higher levels of anxiety, low self-esteem and lack of interpersonal skills may cause these children to become troublemakers at school, even when they have perfectly normal intelligence levels (Cho \& Jang, 2000).

As such, many Korean-Chinese children living in China are undergoing various types of psychological and social difficulties that arise from several different reasons. Hyang Lee (2012), Ok-hee Park (2004), and Cheol-su Huh (2002) conducted studies to learn about the psychological and social traits of Korean-Chinese children, focusing on levels of life satisfaction and stress. Based on their findings, all three called for the need for psychological counseling and intervention.

Against this backdrop, this study seeks to identify the effect of group sandplay therapy in improving quality of peer relationships and reducing behavioral problems of Korean-Chinese children in China. Sandplay therapy is a play therapy technique in which children play with different figures inside a sand tray with set dimensions. It is based on a 
Journal of Symbols \& Sandplay Therapy, Vol.9 No.2.

theory of analytical psychology which states that during sandplay, human unconsciousness is expressed through symbols, and that inner wounds and behavioral problems are resolved through the sense of touch and the symbols that are displayed through the sense of touch (Kalff, 1980 \& 1966).

In addition, sandplay therapy is a non-directive intervention, meaning the clients can remedial and positive experience can be facilitated with through acceptance, empathy and support of the therapist as well as a trust-based relationship between the client and the therapist. As a result, clients can express their negative emotions in a free and secure setting, which allows them to address negative thoughts and emotions. In other words, sandplay therapy gives clients an opportunity for self-reflection and individual growth, which allows them to express and accept themselves in a more positive view (Lee \& Jang, 2015; Park, 2008).

In group sandplay therapy, where there are two or more clients creating a sandpicture at the same time, the focus is on the "relationship." Sand is a safe, self-expressive instrument that helps address emotional problems (Yoo \& Park, 2010). Participants who experience peer support during group sandplay demonstrate lower levels of anxiety and withdrawal, with higher levels of security (Choi, 2015). Prior studies revealed that group sandplay therapy is effective in treating some common problems of children who are addicted to smartphones, such as peer attachment problems, depression and anxiety (Shin \& Jang, 2016; Kim \& Kim, 2015). It also produced positive results in improving ego resilience of university students in China (Wang, et al., 2017); improving emotional and behavioral development of elementary school students in Iceland (Unnsteinsdóttir, 2012); enhancing resilience and psychological health of teenagers in Nepal who survived earthquakes (Lee, 2017); and addressing anxiety, depression, and self-expression issues of immigrant women (Jang \& Kim, 2011). The wide range of participants in these studies demonstrate the applicability of group sandplay therapy across different cultures.

Another reason why sandplay therapy takes on greater importance going forward is that there is a need for psychological intervention that does not involve language. In the present Korean-Chinese community, both the Chinese and Korean languages are used interchangeably, but as the population shrinks, greater effort is being made to blend into the larger Chinese society. Accordingly, the younger Korean-Chinese are far more comfortable using 
Chinese than the local form of Korean used by older generations. But language is not a huge concern for sandplay therapy; children who have difficulty in expressing themselves verbally can freely express their emotions during sandplay therapy. Although it is true that many Korean-Chinese children are fluent Korean speakers from their exposure to popular Korean media with the global reach of Hallyu, or the Korean Wave, they still may find it challenging to articulate their emotions for many different reasons. Sandplay therapy is therefore an excellent way to perform psychological therapy on Korean-Chinese children.

This study aims to help Korean-Chinese children living in China overcome psychological and social hardships through group sandplay therapy that involves children of similar age groups.

\section{П. Research Method}

\section{A. Participants}

With the help of educational institutions in Yanbian, a campaign was launched to promote the study to Korean-Chinese parents in the area through which the intention, aim and overall procedure of the study were introduced. To qualify as a participant, a child had to be between the ages of 9 and 15, and available for all sandplay sessions. After receiving applications, a total of 24 participants were selected, 12 each for the experimental and control groups. Taking account of the nature of group sandplay therapy and the stage of development the children are in, the experimental group was further divided into 3 subgroups with 4 participants each through a prior interview.

There was no significant difference in the age or gender composition of the experimental group and control group. The following table shows the results of a homogeneity test on the demographic features of the two groups: 
Journal of Symbols \& Sandplay Therapy, Vol.9 No.2.

Table 1. Results of homegeneity test on gender and age

\begin{tabular}{ccccccc}
\hline Feature & Group & $\mathrm{N}$ & Mean Rank & Sun of Ranks & Mann-Whitney & $Z$ \\
\hline \multirow{2}{*}{ Age } & Experimental & 12 & 11.50 & 138.00 & \multirow{2}{*}{60.00} & -.92 \\
\cline { 2 - 5 } & Control & 12 & 13.50 & 162.00 & & \multirow{2}{*}{70.50} \\
\hline \multirow{2}{*}{ Gender } & Experimental & 12 & 12.63 & 151.50 & -.09 \\
\cline { 2 - 5 } & Control & 12 & 12.38 & 148.50 & & \\
\hline
\end{tabular}

B. Tools

\section{1) Measuring quality of peer relationships}

The Network of Relationships Inventory (NRI), originally developed by Furman and Buhrmester (1985) and adapted by Jin-kyung Kim and Ahn-jin Yoo (2002), was used to measure the quality of peer relationships. The NRI consists of a total of 40 questions. 20 of them are related to positive qualities of peer relationships, including companionship, intimate disclosure, emotional support, addressing conflict, popularity, and satisfaction. The other 20 are related to negative qualities such as conflict, confrontation, dominance, stubbornness, exclusion, and dissatisfaction. It is a self-reporting measurement in which participants respond to a 4-point Likert scale. The overall confidence level of the measurement of quality of peer relationships in this study, based on an internal consistency estimate using Cronbach's alpha, was .83.

\section{2) Measuring behavioral problems}

The Child Behavior Checklist 6-18 (CBCL 6-18) was used to measure behavioral problems. The CBCL 6-18 is a standardized tool that measures a child's level of competence and behavioral problems by having the primary caregiver respond to questions about the child. First introduced in Korea as ASEBA in 2000, CBCL 6-18 is now commonly used (ASEBA, 2016). The CBCL 6-18 is largely divided into two parts: measurement of behavioral problems and measurement of competence. The measurement of behavioral problems is further divided into syndrome scales, DSM-oriented scale and special behavior problem scales. The syndrome scales measure internalizing problems (anxious/depressed, withdrawn-depressed, and somatic complaints), externalizing problems (rule-breaking, aggressive-behavior), social problems, thought 
problems, attention problems, and others. The questionnaire is made up of a total of 118 questions, and the responses should be based on the child's behavior during the most recent six months. The respondent checks on the most appropriate score on a 3-point Likert scale, which includes 0 (not at all), 1 (sometimes), and 2 (very often). The CBCL 6-18 was also used in an existing research that studied the history of psychological development of Korean-Chinese children in China (Jung, Kim \& Lim, 2011). The overall confidence level based on an internal consistency estimate using Cronbach's alpha was .90 .

\section{Research Procedure}

Pretests and posttest were conducted before and after the actual program to quantify the impact of group sandplay therapy on improving quality of peer relationships and reducing behavioral problems of Korean-Chinese children in China. The 12 participants in the experimental group participated in eight sandplay sessions, where were conducted two to three times a week, 80 minutes per session. The test venue was one of the educational facilities that initially provided assistance in promoting the research to the Yanbian community, and everything needed for sandplay therapy was set up beforehand. In order to understand individual differences and to identify participants who may be unsuitable for the study, interviews were conducted prior to actual testing. The interviews also served as an opportunity for the therapists to build rapport with the participants. The entire process was documented and recorded with the consent of all participants.

\section{Data Analysis}

The SPSS 20.0 statistical program was used to process the results of the test. The Mann-Whitney $\mathrm{U}$ test was used to verify the demographic homogeneity of the experimental and control groups. In addition, the Wilcoxon signed rank test and analysis of covariance were administered to verify the differences in the quality of peer relationship and behavioral problems before and after group sandplay therapy.

The research involved qualitative case studies in which the researcher identifies different 
Journal of Symbols \& Sandplay Therapy, Vol.9 No.2.

implications and themes from the sandpictures produced by the participants. The qualitative case study methodology involves examining the issue at hand by looking into more than one real case in a confined space or context (Creswell, 2007). In this study, individual cases were analyzed using data from a range of sources, including pre-interviews and daily logs and photographs taken during sandplay sessions. Two therapists with more than ten years of field experience took part in the qualitative analysis.

\section{Result and Interpretation}

\section{A. Peer relationships}

The results of the pretest and posttests that were performed to verify the effectiveness of group sandplay therapy on Korean-Chinese children living in China are shown in Table 2.

After therapy, significant difference was found in both positive and negative qualities of peer relationships, including companionship, intimate disclosure, emotional support, popularity, conflict, dominance, stubbornness and exclusion. More specifically, companionship ( $\mathrm{Z}=-2.41$, $\mathrm{p}<.05)$, intimate disclosure $(\mathrm{Z}=-3.08, \mathrm{p}<.01)$, emotional support $(\mathrm{Z}=-2.81, \mathrm{p}<.01)$ and popularity $(\mathrm{Z}=-2.12, \mathrm{p}<.05)$ were significantly improved among the positive qualities, while conflict $(\mathrm{Z}=-2.73, \mathrm{p}<.01)$, dominance $(\mathrm{Z}=-2.04, \mathrm{p}<.05)$, stubbornness $(\mathrm{Z}=-2.53, \mathrm{p}<.05)$ and exclusion $(\mathrm{Z}=-2.13, \mathrm{p}<.05)$ were significantly reduced among the negative qualities. The test results indicate that group sandplay therapy has a positive effect on the quality of peer relationships among Korean-Chinese children in China.

\section{B. Behavioral problems of Korean-Chinese children in China}

The results of the pretests and posttests that were performed to verify the effectiveness of group sandplay therapy on behavioral problems of Korean-Chinese children living in China are shown in Table 3.

Differences were found in all variables for the experimental group, with the exception 
Yeo Reum Lee $\cdot$ Mikyung Jang $\cdot$ Jonghee Shim / The Effectiveness of Group Sandplay Therapy on Quality of Peer Relationships and Behavioral Problems of Korean-Chinese Children in China

Table 2. Differences in quality of peer relationships before and after sandplay therapy

\begin{tabular}{|c|c|c|c|c|c|c|}
\hline & Subdomains & Group & $\mathrm{N}$ & Pretest M (SD) & Posttest M (SD) & $Z$ \\
\hline \multirow{18}{*}{$\begin{array}{l}\text { Positive } \\
\text { qualities }\end{array}$} & \multirow{3}{*}{ Companionship } & Experimental & 12 & $5.17(1.53)$ & $6.42(1.00)$ & $-2.41^{*}$ \\
\hline & & Control & 12 & $5.67(1.37)$ & $5.92(1.38)$ & -1.13 \\
\hline & & $Z$ & 24 & -.51 & & \\
\hline & \multirow{3}{*}{ Intimate disclosure } & Experimental & 12 & $9.50(1.73)$ & $11.92(1.16)$ & $-3.08^{* * *}$ \\
\hline & & Control & 12 & $10.67(2.39)$ & $10.75(2.56)$ & -0.35 \\
\hline & & $Z$ & 24 & -1.73 & & \\
\hline & \multirow{3}{*}{ Emotional support } & Experimental & 12 & $20.83(4.26)$ & $24.17(4.06)$ & $-2.81^{* *}$ \\
\hline & & Control & 12 & $21.33(3.98)$ & $22.25(3.67)$ & $-2.05^{*}$ \\
\hline & & $Z$ & 24 & -.29 & & \\
\hline & \multirow{3}{*}{ Addressing conflict } & Experimental & 12 & $2.42(1.08)$ & $2.75(0.87)$ & -0.88 \\
\hline & & Control & 12 & $2.75(0.97)$ & $2.50(0.52)$ & -1.34 \\
\hline & & $Z$ & 24 & -.75 & & \\
\hline & \multirow{3}{*}{ Popularity } & Experimental & 12 & $5.00(1.54)$ & 6.17 (1.64) & $-2.12^{*}$ \\
\hline & & Control & 12 & $5.50(1.51)$ & $5.33(1.92)$ & -0.54 \\
\hline & & $Z$ & 24 & -.83 & & \\
\hline & \multirow{3}{*}{ Satisfaction } & Experimental & 12 & $8.83(1.78)$ & $9.67(1.56)$ & -1.51 \\
\hline & & Control & 12 & $8.50(1.73)$ & $8.42(1.51)$ & -0.33 \\
\hline & & $Z$ & 24 & -.41 & & \\
\hline \multirow{15}{*}{$\begin{array}{l}\text { Negative } \\
\text { qualities }\end{array}$} & \multirow{3}{*}{ Conflict } & Experimental & 12 & $13.58(2.97)$ & $11.75(3.02)$ & $-2.73^{* *}$ \\
\hline & & Control & 12 & $13.67(2.77)$ & $14.33(3.58)$ & -1.45 \\
\hline & & $Z$ & 24 & -.82 & & \\
\hline & \multirow{3}{*}{ Dominance } & Experimental & 12 & $16.42(2.50)$ & 14.83 (1.99) & $-2.04^{*}$ \\
\hline & & Control & 12 & $16.42(2.84)$ & $16.83(3.46)$ & -0.94 \\
\hline & & $Z$ & 24 & -.73 & & \\
\hline & \multirow{3}{*}{ Stubbornness } & Experimental & 12 & $8.33(1.78)$ & $6.92(1.56)$ & $-2.53^{*}$ \\
\hline & & Control & 12 & $9.17(1.90)$ & $9.58(2.27)$ & -1.27 \\
\hline & & $Z$ & 24 & -.31 & & \\
\hline & \multirow{3}{*}{ Exclusion } & Experimental & 12 & $4.58(1.31)$ & $3.92(1.38)$ & $-2.13^{*}$ \\
\hline & & Control & 12 & 4.17 (1.47) & $4.00(1.28)$ & -1.41 \\
\hline & & $Z$ & 24 & -.41 & & \\
\hline & \multirow{3}{*}{ Dissatisfaction } & Experimental & 12 & $2.25(0.97)$ & $1.75(0.45)$ & -1.73 \\
\hline & & Control & 12 & $2.00(0.85)$ & $2.00(0.95)$ & 0.00 \\
\hline & & $Z$ & 24 & -.52 & & \\
\hline
\end{tabular}

$* p<.05, * * p<.01$ 
Journal of Symbols \& Sandplay Therapy, Vol.9 No.2.

Table 3. Differences in behavioral problems before and after sandplay therapy

\begin{tabular}{|c|c|c|c|c|c|}
\hline Subdomains & Group & $\mathrm{N}$ & Pretest M (SD) & Posttest M (SD) & $Z$ \\
\hline \multirow{3}{*}{ Internalizing } & Experimental & 12 & $67.33(10.25)$ & $56.25(4.60)$ & $-3.06^{* *}$ \\
\hline & Control & 12 & $69.75(10.48)$ & $70.67(11.62)$ & -.10 \\
\hline & $Z$ & 24 & -.72 & & \\
\hline \multirow{3}{*}{ Externalizing } & Experimental & 12 & $61.50(9.73)$ & $54.42(6.39)$ & $-2.81^{* *}$ \\
\hline & Control & 12 & $62.83(13.99)$ & $64.33(13.82)$ & $-2.26^{*}$ \\
\hline & $Z$ & 24 & -.41 & & \\
\hline \multirow{3}{*}{ Anxious/depressed } & Experimental & 12 & $65.17(8.29)$ & $57.08(5.30)$ & $-2.94^{* *}$ \\
\hline & Control & 12 & $67.83(8.96)$ & $68.00(9.80)$ & -.14 \\
\hline & $Z$ & 24 & -.72 & & \\
\hline \multirow{3}{*}{ Withdrawn-depressed } & Experimental & 12 & $65.83(6.24)$ & $57.83(4.90)$ & $-3.07^{* *}$ \\
\hline & Control & 12 & $68.50(6.24)$ & $69.00(8.66)$ & -.68 \\
\hline & $Z$ & 24 & -.73 & & \\
\hline \multirow{3}{*}{ Somatic complaints } & Experimental & 12 & $56.83(5.59)$ & $54.25(4.71)$ & -1.53 \\
\hline & Control & 12 & $58.50(7.35)$ & $58.75(7.50)$ & -.27 \\
\hline & $Z$ & 24 & -.44 & & \\
\hline \multirow{3}{*}{ Social problems } & Experimental & 12 & 69.75(15.95) & $56.42(6.76)$ & $-2.08^{*}$ \\
\hline & Control & 12 & $63.33(6.15)$ & $63.83(6.66)$ & -1.29 \\
\hline & $Z$ & 24 & -.26 & & \\
\hline \multirow{3}{*}{ Thought problems } & Experimental & 12 & $61.25(6.17)$ & $56.92(5.28)$ & $-2.38^{*}$ \\
\hline & Control & 12 & $63.00(8.90)$ & $63.75(8.92)$ & -1.13 \\
\hline & $Z$ & 24 & -.54 & & \\
\hline \multirow{3}{*}{ Attention problems } & Experimental & 12 & $61.50(7.35)$ & $55.58(9.77)$ & $-2.05^{*}$ \\
\hline & Control & 12 & $59.75(5.88)$ & $51.75(18.52)$ & $-2.02^{*}$ \\
\hline & $Z$ & 24 & -.77 & & \\
\hline \multirow{3}{*}{ Rule-breaking } & Experimental & 12 & $59.67(7.20)$ & $56.17(5.86)$ & $-2.02^{*}$ \\
\hline & Control & 12 & $59.92(9.25)$ & $62.75(9.35)$ & $-2.02^{*}$ \\
\hline & $Z$ & 24 & -.18 & & \\
\hline \multirow{3}{*}{ Aggressive-behavior } & Experimental & 12 & $60.00(7.33)$ & $54.58(5.11)$ & $-2.81^{* *}$ \\
\hline & Control & 12 & $62.08(8.95)$ & $62.83(9.00)$ & -1.79 \\
\hline & $Z$ & 24 & -.70 & & \\
\hline \multirow{3}{*}{ Others } & Experimental & 12 & $60.25(6.73)$ & $55.33(4.81)$ & $-2.17^{*}$ \\
\hline & Control & 12 & $59.67(7.80)$ & $60.08(7.82)$ & -.54 \\
\hline & $Z$ & 24 & -.15 & & \\
\hline \multirow{3}{*}{ Total } & Control & 12 & $64.83(7.48)$ & $55.17(5.11)$ & $-3.06^{* *}$ \\
\hline & Experimental & 12 & $67.92(12.50)$ & $69.00(12.83)$ & $-2.23^{*}$ \\
\hline & $Z$ & 24 & -.67 & & \\
\hline
\end{tabular}

$* p<.05 * * p<.01$ 
of somatic complaints, but differences were also found in the control group for the total score, externalizing problems, attention problems, and rule-breaking. This indicates that for these particular variables, the differences found in the experimental group cannot be attributed to group sandplay intervention. In sum, it can be concluded that group sandplay therapy reduces the following behavioral problems: internalizing problems $(\mathrm{Z}=-3.06, \mathrm{p}<.01)$, anxious/depressed $(\mathrm{Z}=-2.94, \mathrm{p}<.01)$, withdrawn/depressed $(\mathrm{Z}=-3.07, \mathrm{p}<.01)$, social problems $(\mathrm{Z}=-2.08, \mathrm{p}<$ $.05)$, thought problems $(\mathrm{Z}=-2.38, \mathrm{p}<.05)$, aggressive-behavior $(\mathrm{Z}=-2.81, \mathrm{p}<.01)$ and others $(\mathrm{Z}=-2.17, \mathrm{p}<.05)$.

\section{Expression of themes}

During group sandplay therapy in this study, participating Korean-Chinese children exhibited a variety of themes with sandpictures, sometimes displaying many themes at once. The different themes exhibited by participants collected from video recordings and photographs taken throughout the entire process were qualitatively analyzed, and some major, common themes were identified. The eight common themes were emptiness, disconnection/separation, concealment, hindrance/obstruction, connection, upbringing, energy and integration/adaptation.

\section{1) Emptiness}

In the physical sense, emptiness refers to a space that is empty, with nothing in it. The emotions expressed by children who display emptiness during sandplay lack curiosity or passion. They use only one side of the sand tray or depict an empty space. In this particular study, participants created sandpictures of empty parks, isolated islands, and empty lakes. In some cases, children used only a small part of the sand tray area.

"Well, here is a unicorn, and a snake..." (Using only the front part of the tray, Child F, Session 1)

"This is a village where people live." (Using only the right half of the sand tray, Child I, Session 1)

"This is a pyramid in the desert. It's thirsty and hot." (Child I, Session 7) 
Journal of Symbols \& Sandplay Therapy, Vol.9 No.2.

"This is just $\cdots$ a lake. It's just $\cdots$ quiet $\cdots$ there's nature $\cdots$ it's quiet." (Child J, Session 4)

"It's an empty place. There's no quiet when there's too much stuff." (Child I, Session 6)

Table 4. Scenes of emptiness

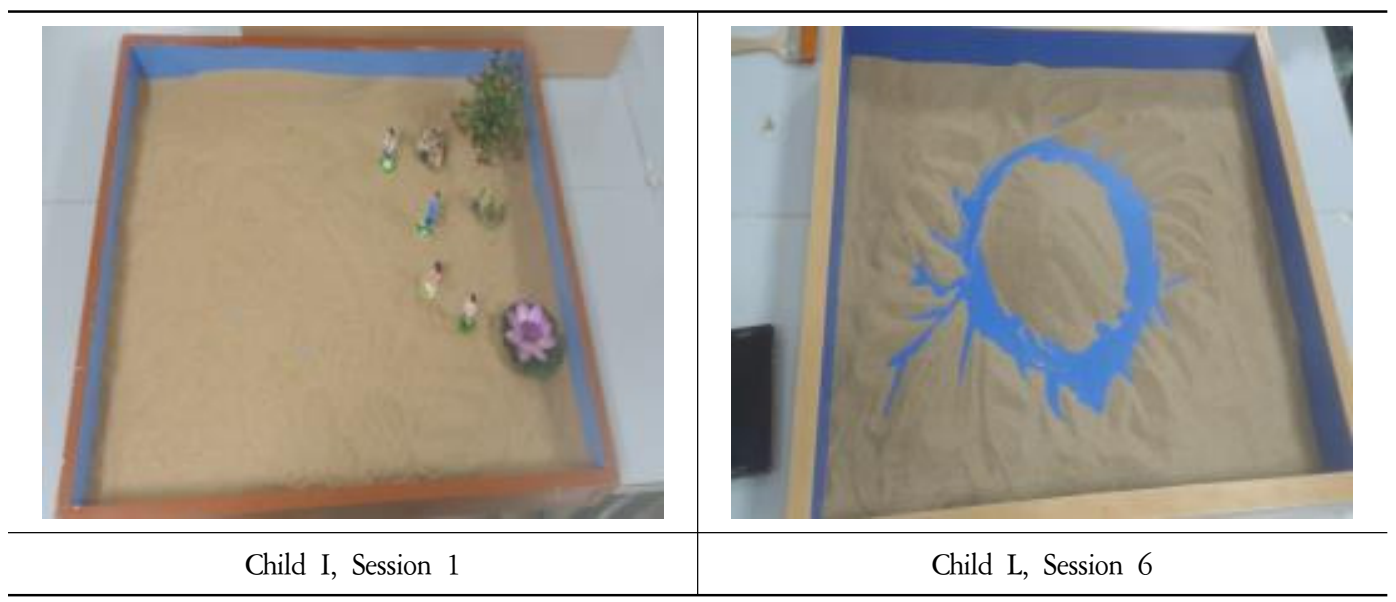

Emptiness is found in Korean-Chinese children living in China who do not have the time and energy to look after themselves due to the pressure to excel academically and get into good schools. Emptiness is also commonly found in children who experienced separation at a young age and do not have someone to steadily rely on (Kernberg, 1975). Developing attachment based on trust is fundamental to building relationships with others in the broader society, and has a lasting, significant impact on peer relationships that are particularly important in childhood.

\section{2) Disconnection/separation}

In a state of disconnection, a person does not interact or get along with others. In a state of separation, a person is disconnected and detached. In sandplay, different parts of a sandpicture are disconnected or stand independently, and there are interruptions in the flow of energy. Participants in this study created sandpictures of isolated islands that cannot be reached without a boat, animals locked inside a cage, a helicopter high above the sky, and a black-and-white separation of "good" places and "bad" places. 
Yeo Reum Lee $\cdot$ Mikyung Jang $\cdot$ Jonghee Shim / The Effectiveness of Group Sandplay Therapy on Quality of Peer Relationships and Behavioral Problems of Korean-Chinese Children in China

"I'm keeping the goat inside the fence because it ate up all the grass. For the cow $\cdots$ well... I don't want it out because it may cause trouble." (Child A, Session 2)

"The airplane has to stay up here because it'll break down if it comes down." (Child E, Session 6)

"This is the ocean and this is the river." (Child G, Session 5)

"This is a dangerous area; that area is not, and I want them to stay far away from each other." (Child I, Session 3)

"This is an area for two people. You cannot enter alone." (Child L, Session 1)

\section{Table 5. Scenes of Disconnection/Separation}

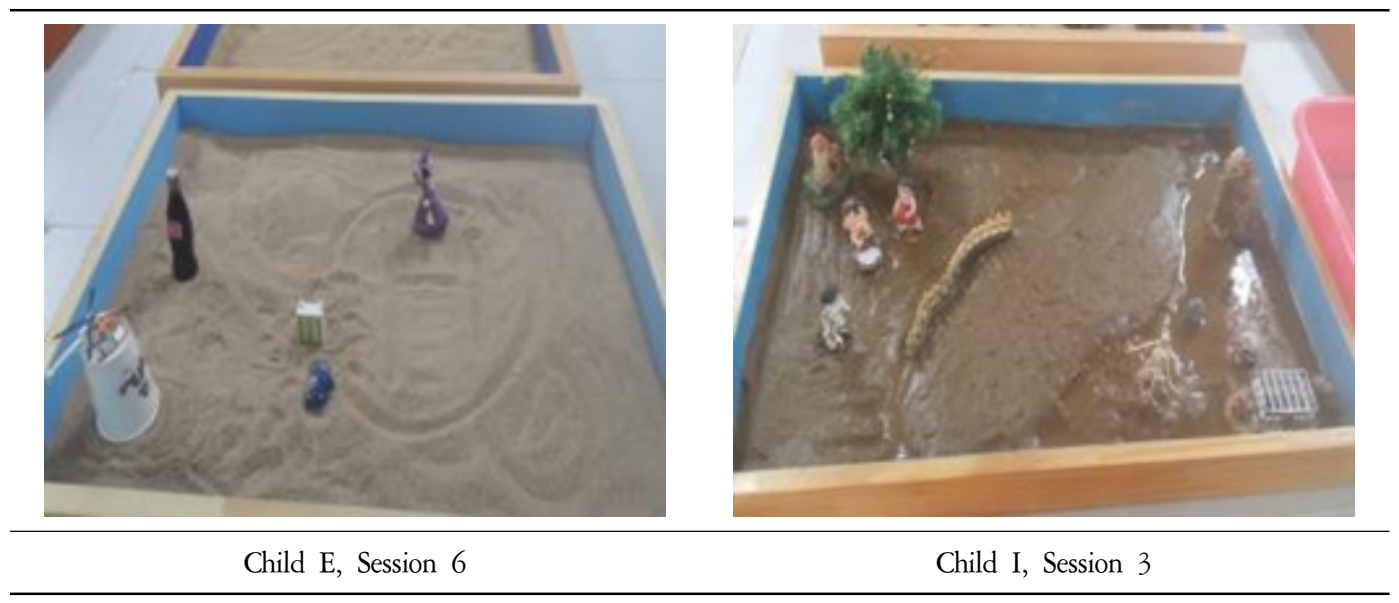

The sandpictures created by participants who demonstrate disconnection/separation show that these children are emotionally withdrawn, reluctant to form relationships or engaging in limited relationships only.

\section{3) Concealment}

Concealment refers to the act of covering something up or hiding something. In the context of sandplay, children who demonstrate concealment bury figures inside the sand or hide them. The participants in this study displayed concealment by creating tombs, jewels buried under the ground, and butterflies or jewels hidden under the sand at a beach. 
Table 6. Scenes of concealment

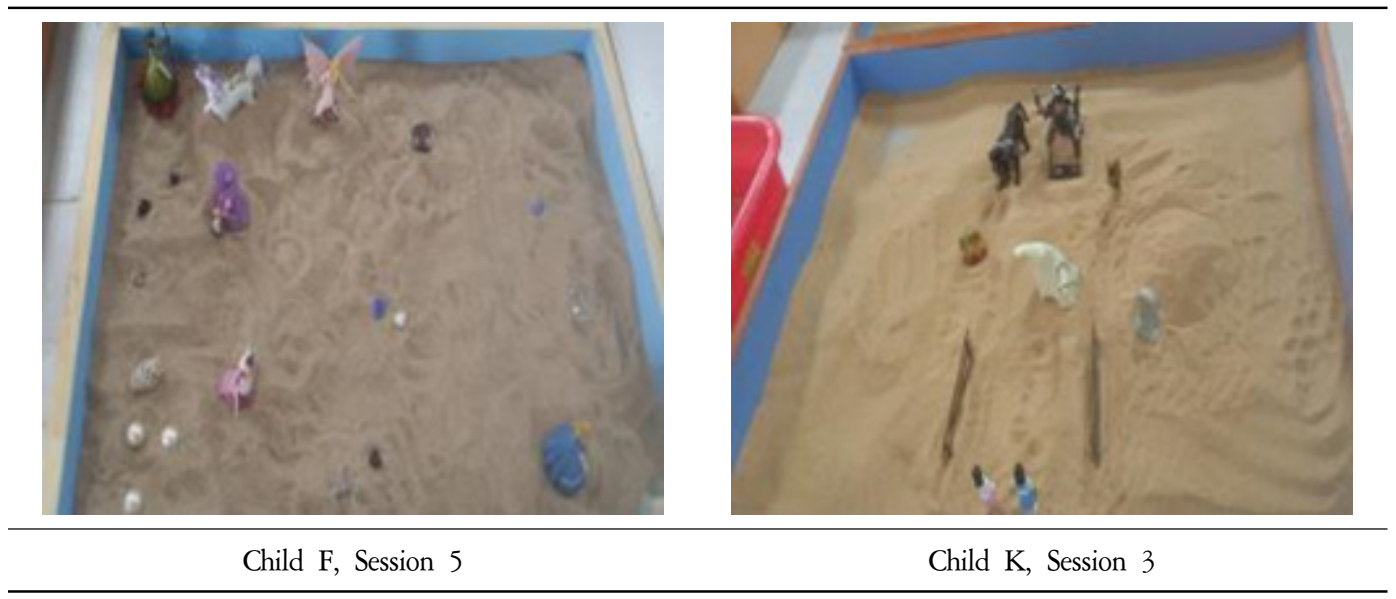

“There's a jewel bidden bere." (Child C, Session 6)

"These are tombs." (Butterflies and jewels buried in the corners of the sand tray, Child F, Session 4)

"These people were taken by a witch and they find these pearls'. this is what's important here, finding them is the only thing that matters." (Burying pears on the right side of the tray and covering them up with sand, Child F, Session 5).

"This is a haunted house. There are tombs... things I hate the most." (Child K, Session 3)

The participants buried something under the sand and wanted someone to find it. This has many implications in sandplay therapy. Hiding figures or other objects may be an act of trying to protect something that matters, or it may be an effort to hide something that the child wants to get away from, which indicates helplessness. However, there may also be the intention to bring about change. It may be a signal that ego differentiation is about to begin, and that a new stage of growth and rebirth lies ahead. Thus, a positive interpretation is also possible. When ego differentation occurs, thought and emotion come to a balance. The child begins to understand that there is a distinction between oneself and others, keeps appropriate borders and is able to maintain healthy relationships without being swayed by others' opinions. This can positively impact the child's peer relationships. 


\section{4) Hindrance/obstruction}

Hindrance and obstruction are barriers to new growth and development potential. The participants in this study displayed hindrance/obstruction by creating sandpictures that depict a witch interfering at court, a witch trying to steal jewels from a princess, bad people starting war, a haunted house, a monster trying to steal jewels from a pyramid, a villain trying to break into a tower, etc.

Table 7. Scenes of hindrance/obstruction

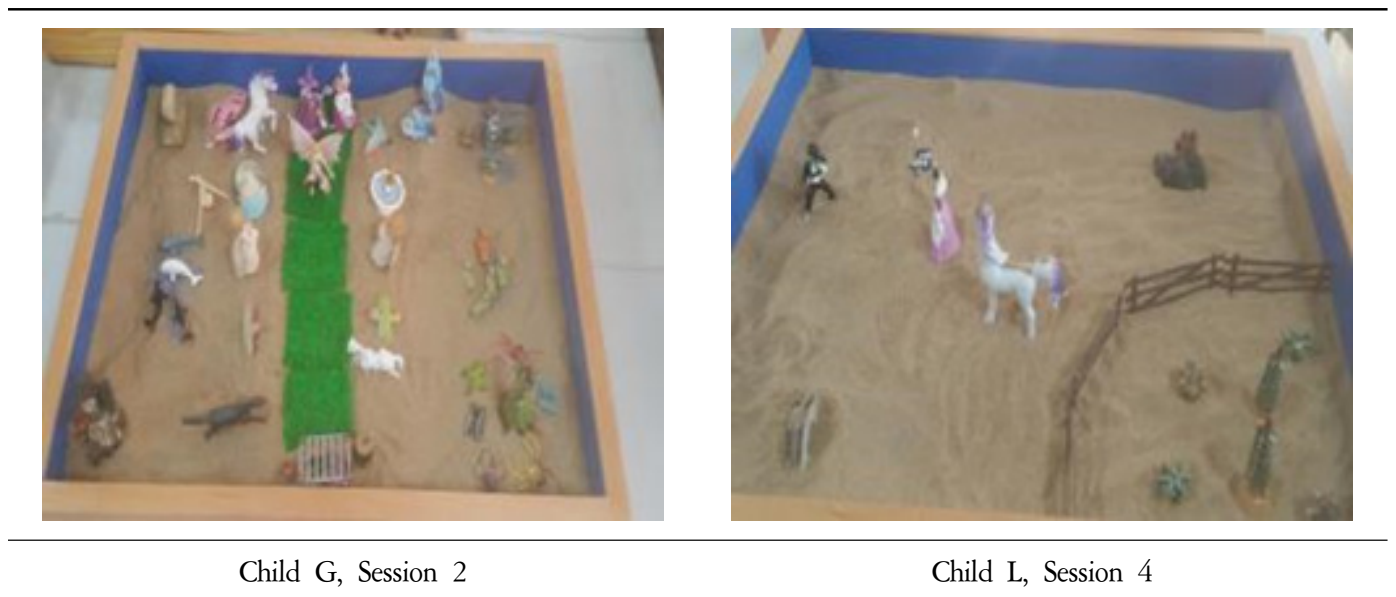

"The sorcerer stopped the water from coming out." (Child A, Session 6)

"A witch is trying to overturn the trial on the villain who tried to kill the princess." (Child

$G$, Session 2)

"Well $\cdots$ the volcano erupted and killed all the dinosaurs." (Child H, Session 3)

"The Indian village in invaded." (Child J, Session 1)

"This country has water shortage. All the fish are going to die." (Child K, Session 6)

"The villains are trying to break through the tower." (Child L, Session 4)

For all things that hinder or obstruct, there are bound to be somethings that fight back; in other words, there are inevitably confrontations and struggles. The theme of hindrance/obstruction may imply the child's ego becoming separated from the maternal energy in their unconscious. When a child, who is withdrawn and depressed in overly competitive 
Journal of Symbols \& Sandplay Therapy, Vol.9 No.2.

environments under overprotective mothers, engages in a conflict when facing this new aspect inside oneself; the two energies collide. Most participants in this study asserted that the good will win and the bad will be defeated, indicating that their new, positive internal energy is becoming bigger.

\section{5) Connection}

Connection is the state in which objects or phenomenon are linked or related to one another. In sandplay, it is demonstrated by forming links and relationships between figures. Most participants in this study displayed connection with a bridge. As the sessions went on, some participants started to make a bridge out of sand and not figures.

"The horse is crossing here." (Child B, Sessions 5 \& 6)

"This is an undersea carriage that takes sea creatures around." (Child D, Session 7)

"This is the path that the unicorn and fairy can take to get from here to there." (Child F, Session 8)

"The witch is on that side, and the princess is on this side. The witch is trying to cross the bridge to come and steal the princess's jewels." (Child G, Sessions 6 \& 7)

"The knights are trying to bring food by boat." (Child H, Session 7)

"I wanted to lay a bridge, but couldn't find one I like so I just used this. I think it'll be much better with a real bridge." (Child J, Session 2)

"This is a village only for women, and that village only for men. There's a bridge connecting the two villages. Isn't it fun?" (Child K, Session 7)

"The bottom part is an orchard or a farm and the upper part is the village. There is a wide river in between and the people can use the submarine to cross it." (Child I, Session 7)

In a state of connection, relationships or different psychic elements of a child unite. When two polarities meet, the center of the Self, or the core of our personality, is stimulated. The energy of the Self links and brings together the opposite energies. When this happens, a child comes to discover and accept different realms within oneself, learning to understand oneself as well as others with a broader view. Children who have broader views on others can move away from one-sided peer relationships toward more balanced relationships. Connection may also indicated an attempt to initiate a new relationship. 
Table 8. Scenes of connection

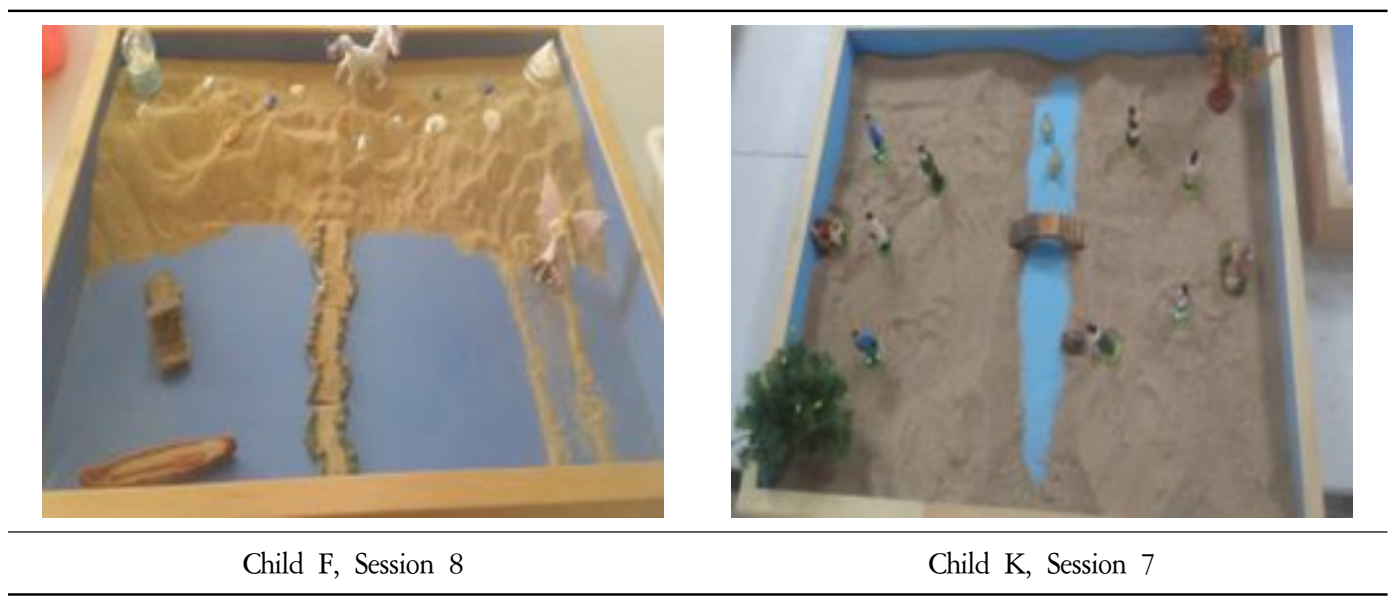

\section{6) Upbringing}

Upbringing is the act of caring for and raising a child. It includes everything that helps a child grow and develop, such as nurturing, protecting and providing help. In this study, participants displayed the theme of upbringing by creating sandpictures of people taking care of a baby or livestock, and sandpictures with parent figures.

"The carriage is delivering a cake'.' three people are taking care of the baby." (Child A, Session 4)

"The person taking care of the baby reads to him and turns on music for him, too." (Child A, Session 6)

"They are feeding the horse." (Child C, Session 5)

"The carriage is delivering food to people at a picnic." (Child C, Session 6)

"The mom and dad had a baby. They are telling a story to the baby." (Using food figures, Child D, Sessions 1, 2, 3, 4, 5 \& 8)

Scenes of people going somewhere to get food (Child H, Sessions 5, 6, 7 \& 8)

"The family is enjoying food by the lake." (Child J, Session 8)

By exhibiting scenes of upbringing during sandplay, Korean-Chinese children who were separated from their parents in early childhood and who now cannot afford to look after their emotions in an overly competitive education environment had the chance to explore themselves 
Journal of Symbols \& Sandplay Therapy, Vol.9 No.2.

Table 9. Scenes of upbringing

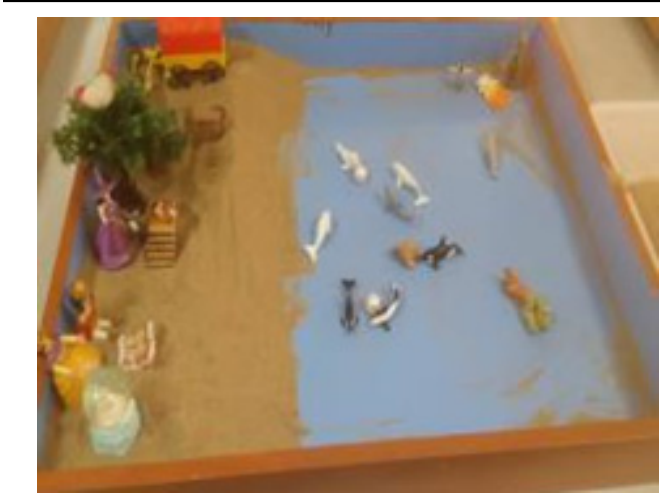

Child D, Session 8

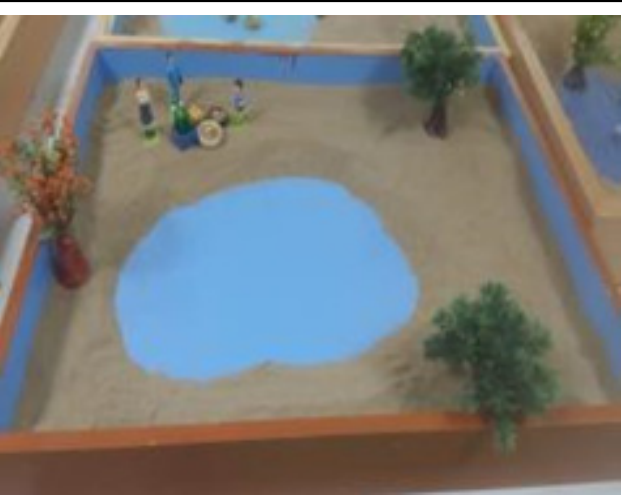

Child J, Session 8

and nurture their premature ego.

\section{7) Energy}

Energy is the source of human activity. In sandplay, it is expressed in forms of vitality and liveliness. In some sandpictures, energy creates change or a new form of energy is born. In this study, energy was exhibited in sandpictures that depict sorcerers transforming objects, fountains and volcanos.

Table 10. Scenes of energy

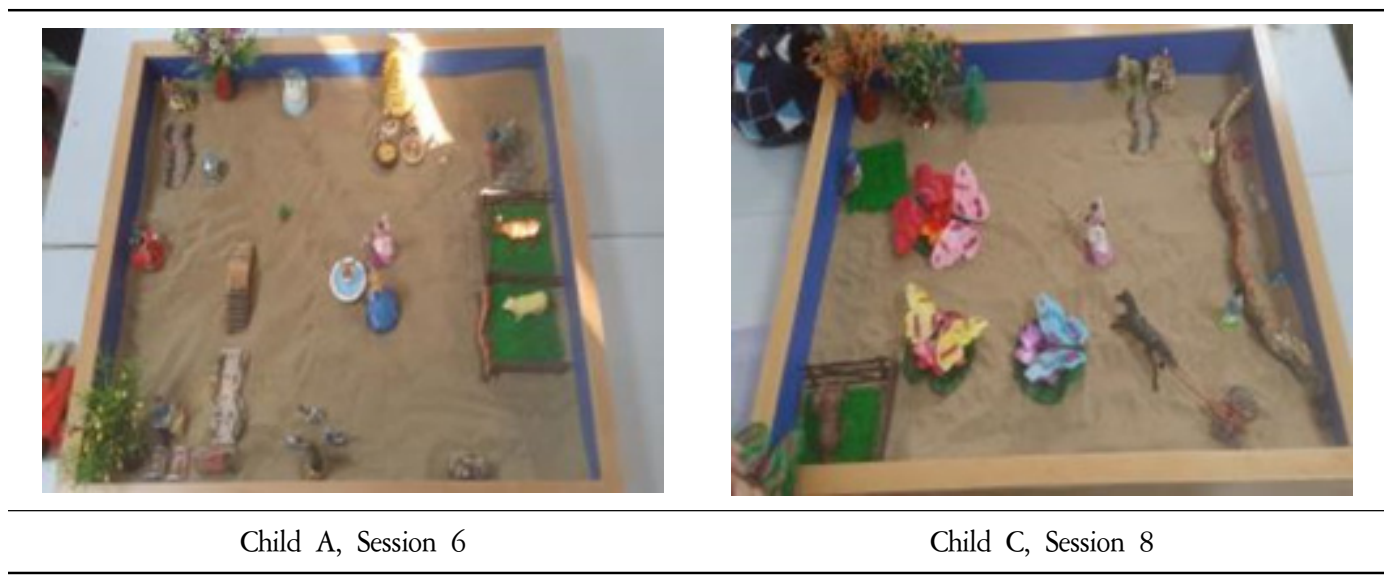


"The sorcerer dried up the water but water is springing up from the fountain." (Child A, Session 6)

"The sorcerer blew up the size of the flowers and butterflies, and the horse is startled." (Child

C, Session 8)

"Dolphins are springing up from the fountain." (Child E, Session 4)

"A spark appeared on the volcano. Now the fire is going to ravage." (Child L, Session 5)

Energy is exhibited when children discover a new energy within themselves and attempt to use that energy in various ways. It may also be an indication that the energy is bursting from within. Using positive energy from within can help address psychological difficulties by allowing the child to look into themselves to resolve external problems.

\section{8) Integration/adaptation}

In a state of integration/adaptation, different elements come together as an organization and make up a whole, in a way that suits the surrounding environment and way of life. In this study, participants created sandpictures of people adjusting to society and everyday life.

"The two children lost their parents, who died on the ocean. One grew up to be a sorcerer and the other became a princess. The sorcerer uses magic to make food come out from a bucket." (Child

A, Session 7)

"A family lives here. The dad bought the house for the family." (Child D, Session 7)

"People are gathered here to watch the fish swim." (Child I, Session 8)

"The family is having a picnic by the lake." (Child J, Session 7)

"They are going to school. They'll learn how to dance and do magic. I think it'll be fun." (Child K, Session 1)

"They bought a bouse near the beach. These are people at the beach." (Child K, Session 8)

Manifestations of integration/adaptation to everyday life are often found during the concluding stages of sandplay. This indicates that the client has entered the realm of the unconscious and is reorganizing the archetypes and the different elements of their psyche (Turner, 2005). According to Turner (2005), adaptation could indicate the dynamics related to 
Table 11. Scenes of integration/adaptation

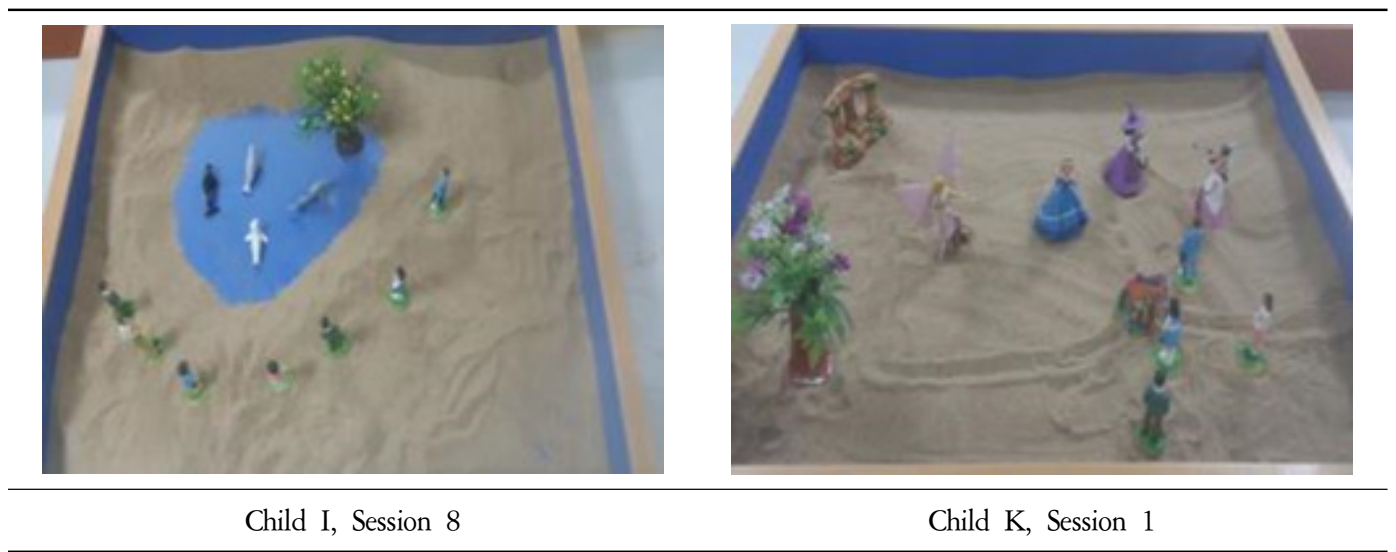

the relationship between the ego and the external environment. When a client goes through the process of individuation during sandplay therapy, the ego adapts to the external environment in a direction consistent with the Self. Through the theme of adaptation, clients extend the integration of their inner psychic world experienced during sandplay to everyday life.

\section{Summary and Conclusion}

This study focused on verifying the effectiveness of group sandplay therapy on the quality of peer relationships and behavioral problems of Korean-Chinese children in China. Through an analysis of the different themes exhibited by the participants during sandplay, the following conclusions were reached:

First, most of the variables that affect the quality of peer relationships were improved after group sandplay therapy, confirming the effectiveness of group sandplay therapy in improving quality of peer relationships. The relationships developed with the therapists and other participants in a group sandplay setting allow participants to become more open and express themselves better, which possibly had a positively impact on the quality of their peer relationships. 
Second, group sandplay therapy was found to be effective in reducing the following behavioral problems: internalizing problems, anxious/depressed, withdrawn/depressed, social problems, thought problems, aggressive-behavior and other problems. Participants in group sandplay therapy were able to express their inner emotions and release their suppressed energies in a constructive manner, which had positive impact in improving their behavioral problems.

Last but not least, the study identified some common themes displayed by the participants during sandplay. The common themes were emptiness, disconnection/separation, concealment, hindrance/obstruction, connection, upbringing, energy and integration/adaptation. These themes represent the common psychological characteristics of Korean-Chinese children living in China.

To date, most studies on Korean-Chinese children in China focused on the need for psychological intervention, suggesting future challenges and directions that need to be taken. There are hardly any studies that look into the effectiveness of counseling or therapy centered on altering their psychological states or relationships. For the parents of the participants, this study served as an opportunity for them to learn about the importance of psychological intervention on children. It also was an opportunity for Korean-Chinese children in China, who live in a highly competitive educational environment, to concentrate on their inner emotions and nurture their premature personality and ego.

With ongoing changes in the Korean-Chinese community in China, traditional ways of thought and behaviors are no longer effective in addressing problems that occur within individuals or groups. Schools are not an exception, and they must also change their approach in guiding students to meet the demands of a rapidly changing society. However, many teachers lack understanding and are unwilling to cooperate, the counseling staff lack expertise, and support facilities and systems are inadequate. These realities restrict the benefits of student guidance and counseling services (Chae, 2002). This study offers an opportunity to learn about the importance of psychological counseling on Korean-Chinese children in China, and provides experience-based lessons on appropriate measures of early intervention and counseling.

Nonetheless, there remain some limitations to this study and suggestions that follow. First, the group sandplay therapy was performed on only 12 participants, which makes it 
Journal of Symbols \& Sandplay Therapy, Vol.9 No.2.

difficult to generalize the results to the entire population of Korean-Chinese children living in China. Second, the study was conducted in a limited timeframe and setting. More time and more sandplay sessions are needed to bring real, sustainable benefits to the participants. Third, it was difficult for the therapists to gain a deeper understanding of the participants not only due to cultural and linguistic differences but also the lack of existing studies and materials or information available on the effect of psychological counseling on Korean-Chinese children in China. Fourth, the tools used in this research are either designed or adapted to fit conditions in Korea. Although the language barrier was not a problem, there were still restrictions in applying these tools to Korean-Chinese children. Finally, there were limitations in gaining an extensive understanding of each individual client and their individual differences, as group sandplay therapy itself involves multiple participants at the same time. Although individual pre-interviews were conducted to gain an understanding of each and every client, the time was too short to fully grasp their individual differences. Furthermore, fellow participants themselves become variables to each participant, making it difficult to distinguish individual traits at all times.

\section{References}

ASEBA, (2016). www.cbcl.co.kr

Cho, B-H., \& Lee, J-Y. (2005). Developmental Environment and Adjustment of Korean-Chinese

Children Separated from Both Their Parents. Korean Journal of Child Studies, 25(4), 231-245.

Cho, Y-T., \& Jang, J-K. (2000). The Effects on Isolated and Leisure Activities Behavior of Students with Mental Retardation by Functional Using-Based Leisure Activities in inclusive Setting. The Journal of the Korean Association on Developmental Disabilities, 4, 27-40.

Choi, H-M. (2015). Effect of Group Sandplay Therapy on Children's Learned Helplessness and Ego-Resilience. Graduate school master dissertation, Myongii University.

Creswell, J. (2007). Qualitative inquiry and research design 2E: Choosing among five tradition. Sage, Thousand Oaks, CA. 
Furman, W. \& Buhrmester, D. (1985). Children's perceptions of the personal relationships in their social networks. Developmental Psychology, 21, 1061-1024.

Hur, C-S. (2002). The Psychological. Social Characteristics of Korean-Chinese Youth on Yanbian Area in China, and the Tasks of Counseling. Studies on Korean Youth, 13(2).

Jang, M., \& Kim, Y. H. (2012). The effect of group sandplay therapy on the social anxiety, loneliness and self-expression of migrant women in international marriages in South Korea. The Arts in Psychotherapy, 39(1), 38-41.

Jeong, H-W., Kim, M-S., \& Lim, W-S. (2011). A Study of the Psychosocial Characteristics of Children of Low Income Single Parent Families of Korean Ethnicity in Chinese Farming Village. Korea Youth Research Association, 18(1), 323-338.

Kalff, D. (1966). Symbolism and child analysis. Unpublished transcription of seminar at Footlighters' Child Guidance Clinic. Hollywood Presbyterian Hospital, Hollywood, CA.

Kalff, D. (1980). Sandplay: A psychotherapeutic approach to the psyche. Boston: Sigo Press.

Kernberg, O. F. (1975). Borderline Conditions and Pathological Narcis-sism. New York: Aronson.

Kim, H-R., \& Kim, Y-J. (2015). The Effects of Group Sandplay Therapy on Peer Attachment, Impulsiveness, and Social Anxiety of Adolescents Addicted to Smart Phones. Journal of Symbols \& Sandplay Therapy, 6(2), 1-12.

Kim, M-S. (2012). A Study of Factors Influencing Behavioral Problems of Korean-Chinese Children and Chinese Children in Yanbian Area. Korean Journal of Counseling, 13(3), $1141-1157$.

Kim, S-H., \& Jeong, O-B. (2011). Maternal overprotection in relation to child emotion regulation and peer relationship: Focusing on mediating effects of emotional regulation ability. The Korean Journal of the Human Development, 18(3), 69-92.

Ko, Y-J., Kim, Y-S., \& Noh, J-S. (2000). Contribution of Behavioral Disturbance, Peer Acceptance and Friendship to the Self - Perceived Social Competence in Korean Elementary - School Children. Korean Journal of Psychology: Development, 13(2), 65-78.

Lee, B-Y., \& Jang, M-K. (2015). Comparisons between North Korean Adolescent Defectors and South Korean Adolescents in Expressions in Sandplay Therapy. Journal of Symbols \& Sandplay Therapy, 6(2), 31-45. 
Journal of Symbols \& Sandplay Therapy, Vol.9 No.2.

Lee, S-H. (2017). The effect of Group Sandplay Therapy on Psychological Health and Resilience of Young survivors of Nepal Earthquake. Graduate school master dissertation, Namseoul University.

Lee, H. (2012). Life satisfaction and stress according to demographic characteristics of Korean youth in Yanbian, China. Graduate school master dissertation, Korea Baptist Theological University.

Li, M-H. (2015). Status and Prospect: A Research Review on Korean Chinese Transnational Migration - Centered on Chinese Academia. Unification Humanities, 61, 501-522.

Park, S-H. (2008). The Effects of the Sand Play Therapy on Parenting Stress of the Mothers of Developmental Disability Children. Graduate school master dissertation, Daegu University.

Park, O-H. (2000). Characteristics and main causes of youth problems. Youth leaders' training materials for prevention and guidance of youth problems youth in Yanbian, China, 25-39.

Park, O-H. (2004). Analysis of psychological trouble and counseling needs for adolescents in China Yanbian. Graduate school master dissertation, Cheju National University.

Suh, M-H. (2011). A Study on the children's values and nurturing situation of compatriots in China. Research Report of Economic Society for Humanities and Social Sciences.

Shun, G-R., Cho, M-O., \& Yang, J-H. (2004). Qualitative research methodology. Ewha Womans University Press.

Shin, J-H., \& Jang, M-K. (2016). Effect of group sandplay therapy to be addicted youth's addiction levels and anxiety. Journal of Symbols \& Sandplay Therapy, 7(1), 31-45.

Turner, B. A. (2005). The handbook of sandpaly therapy. California: Temenos Press.

Wang, D., Nan, J. K., \& Zhang, R. (2017). Structured group sandplay to improve the resilience of college students: A pilot study. Arts in Psychotherapy, 55, 186-194.

Yang, Y-S. (2014). The effects of sandplay therapy on the behavioral problems, self-esteem, and emotional intelligence of children in grandparents-grandchildren families in rural Korean areas. Journal of Symbols \& Sandplay Therapy, 5(1), 13-25.

You, S-E., \& Park, B-J. (2010). The effect of group sandplay therapy for children's anxiety decrease and ego-resilience promotion. The Journal of Play Therapy, 14(1), 67-88. 
Yeo Reum Lee · Mikyung Jang · Jonghee Shim / The Effectiveness of Group Sandplay Therapy on Quality of Peer Relationships and Behavioral Problems of Korean-Chinese Children in China

Yoo, A-J., Han, E-J., \& Kim, K-J. (2002). Aggression and quality of peer relationships in early adolescents. Korean Journal of Child Studies, 23(3), 79-90.

Received : October 30, 2018

Revised : December 9, 2018

Accepted : December 17, 2018 